\title{
Custody and Treatment in Juvenile Institutions
}

\section{An Organizational Analysis}

\author{
MAYer N. ZaLD \\ Assistant Professor of Sociology, University of Chicago \\ B.A., 1953, University of Michigax; M.A., 1955, University of Hawaii; Ph.D. \\ (Social Psychology), 1960, University of Michigan \\ DAvid Street \\ Assistant Professor of Sociology, University of Chicago \\ B.A., 1957, Northern Illinois University; M.A., 1958, Ph.D (Sociology), 1962, \\ University of Michigan
}

Correctional institutions have two purposes-custody and rehabilitation. This paper attempts to analyze the organizational patterns and problems of juvenile correctional institutions in regard to their goals. The findings of a study of six juvenile institutions for boys indicate that (1) institutions which stress treatment are likely to have a greater delegation of authority and a more complex departmental structure; (2) treatment institutions and organizations which place equal stress on custody and treatment are more likely to have higher levels of conflict among staff; (3) staff in treatment institutions are less distant and domineering with the inmates; and (4) inmates attitudes and groupings are more positive in the treatment institutions.

$\mathbf{C}$

ORRECTIONAL organizations, no matter how much they vary in emphasis, must ultimately have the dual purpose of custody and rehabilitation. If one of them attempts to do away with containment and control, the community and relevant officials will build pressure to reinstate controls. On the other hand, given the values of our society and the original definition of the juvenile institution as rehabilitative, even the most custodial institution has to make some effort to reclaim its youth and use $h u$ manitarian controls. Yet, differences in goals, ranged along a continuum from custody to treatment, have a number of effects on the operation of these organizations.

Organizational analysis, a developing subdiscipline within sociology, directs attention to the broad problems of organizational goals, relations between the organization and its environment, the internal structure of the organization, and relations with and among the clientele. In this article we shall examine the organizational patterns and problems of juvenile correctional institutions, particularly those which have attempted to convert from a custodial to a treatment-oriented type of approach.

Some time ago, we had the oppor- 
tunity to explore this problem in a comparative study of several institutions for male juvenile offenders. ${ }^{1}$ Questionnaires filled in by inmates and staff, historical documents, observations of meetings and organizational practices, extended interviews with executives and others, and consultation with people outside the organization were some of the methods used.

The institutions we studied differed in their goals. Among the four major organizations, one was strongly, even repressively, custodial, emphasizing discipline and hard work; a second was a "moderated custody" institution, beginning to tone down repressive control but not yet committed to a full treatment program; a third emphasized individual treatment; and the last was developing a program of milieu treatment. These institutions, which were located in several states, varied in size-from 400 boys and 180 staff to 75 boys and 40 staff-and were both public and private. In addition, we studied two smaller private institutions which had custodial goals but which were "open" in that they sent their inmates out to ordinary public and parochial schools each day.

Such aspects of organization as departmental structure, balance of power, level and patterns of conflict, staff-inmate relations, and inmate responses to the institutions will be considered both generally and with special reference to those institutions.

1 Detailed findings of the study, which was directed by Robert Vinter and Morris Janowitz, may be found in The Comparative Study of Juvenile Correctional Institutions: A Research Report (Ann Arbor: University of Michigan School of Social Work, 1961). The research was supported by grant M-2104 from the National Institute of Mental Health.

\section{Departmental Structure}

One striking difference between institutions with more custodial goals and those with more treatmentoriented goals is the ease of routinization and coordination of the former. The first reason for this is that inmates in the custodial institutions are rendered more passive by the use of dominating and coercive sanctions, whereas in the treatment institutions staff must be continually adapting to the inmates. Secondly, custodial philosophy provides rules for most situations that will arise, while treatment philosophy requires that each situation be handled in terms of the particular inmate involved. Thirdly, custodial institutions establish programs which hold for large groups of boys, while treatment institutions try to set up programs to meet the needs of each boy. Finally, treatment institutions have continually changing programs which require a great deal of individual coordination of staff and boys. This is in marked contrast to the repetitive programing of the custodial institutions.

These differences in the degree of routinization sharply affect other aspects of the institutions. While in custodial institutions little departmentalization occurs and most personnel report directly to the superintendent or assistant superintendent, in treatment institutions the superintendent's span of control becomes extremely attenuated because he must make so many different kinds of decisions. Thus, the clearly custodial institutions are organized simply, while institutions toward the center of the continuum and institutions utilizing mainly individual treatment have what can be called a "multiple department" structure in which each 
area of the institution-the school, the cottage, the social service, maintenance, business-operates relatively autonomously. Each has a department head who makes decisions for his own area. Both the moderate custodial and the individual treatment institutions are likely to have this type of structure because the activity in one department seems to have no relevance for another. In contrast, in the correctional institution with a program of milieu treatment, all activity with inmates must correspond to that philosophy; thus, action in the school and cottage, for example, must be as treatment-oriented as action elsewhere in the institution. As a result, milieu institutions are likely to have a dual divisional structure: all activity with inmates is placed under a single division head and is guided and supervised by professional treatment personnel, and all business and maintenance staffs are placed in a separate division.

To illustrate these ideas about departmental structure, let us turn specifically to the institutions in our study. The most custodial was only slightly departmentalized. Its farm had a departmental structure, but only so as to achieve better production rather than to supervise staff-inmate relations. The superintendent did not feel hard-pressed to make decisions and spent an hour or two each morning reading the political news. The largest institution in our sample, presently a moderated custodial institution with a multiple department structure, was, at an earlier time, more custodial and had fewer departments, though the size was the same. Indeed, it once resembled our most custodial institution, even though it had over one hundred employees. Department- alization came to this institution when outside pressure groups complained about the autonomy and power of cottage parents in disciplining and treating boys as they wished. In this circumstance, departmental. ization helped the executive establish a reasonable span of control so that he could guarantee appropriate behavior from his staff.

Of course, as institutions get larger they require some greater departmentalization, but size alone does not account for departmentalization, as the case of the moderated custodial organization indicates. Similarly, the individual treatment institution had only forty staff and seventy-five boys; yet it was fully departmentalized and the assistant superintendent, who was the key person in running the institution, was under a great deal of pressure. However, departmentalization did not solve all the problems of executive control. The lack of routinization and the fact that the assistant superintendent was chief disciplinarian put him in the position of having to make decisions about many things every day.

\section{Balance of Power}

How is power distributed among executives and staff groups in the institutions? What are the orientations and values of the people who hold power?

Looking first at the distribution of power among the executives, we note that as the institution becomes more departmentalized, the superintendent finds it more difficult to control and supervise all personnel; consequently, power must be shared. This sharing of power is especially true, therefore, for the treatment institutions, which are not only departmentalized but also in the public eye, in contrast to 
custodial institutions, which tend to be relatively isolated and removed from the public. Treatment institutions generally are involved with a wide range of external agencies and, because of their open policies, superintendents must be prepared to defend their institutions against attack and share their power as a means of building support for their relatively expensive programs.

We found that in the most custodial institution only the superintendent was perceived by the staff as having a great deal of influence among the executives. In three of the institutions studied, an "inside-outside" split in the executive role occurred. The assistant superintendent in each of the two treatment institutions was seen as having a great deal of power; in fact, the number of staff who thought he had a great deal of influence was larger than the number who felt the superintendent had. In the moderate, or intermediate, custodial institution, where the superintendent was ideologically more committed to a treatment goal but was unable to implement this commitment, the second in command-unofficially-was the head of the cottage parents, who had two mottoes: "We're not in the beating business," and "The community has a right to be protected." Thus, in this institution, a person with primarily nonrepressive custodial attitudes was in command. What is important here is that by giving him power, the superintendent could insure containment and control.

In most of the institutions the values of the chief executive and the assistant superintendent tended to parallel the difference in goals. Only in the moderate custodial institution do we see any marked feeling that program and goals were not up to the standards of the figures in power there. The superintendent, for example, felt he had to compromise his aims in order to meet the restricted budget and lack of public support for a more rehabilitative program.

Among staff groups, power distribution took a fairly predictable course. First, in all institutions the teachers and the principal had very little power, reflecting the fact that the schools were relatively isolated from the major operating problems of the organization. Secondly, as we move from the most custodial to the individual treatment institution we see a decreasing amount of power given to cottage parents. Cottage parents have less and less say over discipline, over when the boy goes home, and over what the boy's program should be like. On the other hand, in the milieu institution, where cottage parents participated in the basic decisions, their power was higher than in any of the other institutions. Thirdly, as we move from custodial to treatment institutions, the social service workers move from a position relatively isolated from internal operations, a position in which they deal mainly with the courts and families, to an increasingly central position, in which they make decisions about the boys. He who controls decisions about the boys controls the organization.

Level and Pattern of Conflict

The power balance in an organization is also related to its pattern of conflict. The extent to which the institution is committed to both custodial and treatment goals should be related to the amount or level of conflict there. Many objective observers have noted the apparently irreconcil- 
able conflict among treatment personnel-who tend to be professionals, white-collar workers, and younger people - and the custodial cottage parents over such well-known issues as: Should or shouldn't we lock the doors? Must the boys march? Should boys be allowed to go off grounds? How much should we believe the boys? We made it our job to go beyond mere recognition that institutions are conflict-prone organizations and, instead, attempted to account for differences in their level and pattern of conflict.

Our first notion was that institutions near the middle of the goal continuum, with social service workers in one department and cottage parents in another, should have the highest tension level. Our second was that institutions with custodial goals would have fewer social service workers and, since these few would be isolated from the organization, there would be little conflict. In treatment institutions, we thought that careful selection of cottage parents and the clear dominance of treatment goals and social service workers would lead to a decline in conflict. In other words, we hypothesized that the further away from the end points of the continuum, the more the conflict. We were wrong in this hypothesis because we seriously underestimated the problems of the treatment institution.

First, it is hard to know when one is effective in treating a delinquentone can only know after his means have proved successful ten years later. In other words, good criteria for what means to use are absent in treatment institutions. In the absence of hard criteria, one can debate endlessly about what constitutes apppropriate staff behavior even though there may be a basic agreement on goals. This is not the case in custodial institutions, where there is a clear relationship between the means and the end. Furthermore, because communication and coordination are more important in treatment institutions, the personnel have more of an opportunity to express their differences so that the amount of conflict perceived is higher. Although the conflict may be less virulent and less basic, it nevertheless is likely to exist and to be fairly strong. What we found, then, is that conflict was lowest in our two most custodial institutions and highest in the milieu treatment institution. Of course, idiosyncrasies of the institution may help to account for this, but we would not discount this basic pattern.

What about the pattern of conflict-that is, who conflicts with whom -within the institution? In any organization, conflict is most likely to occur between those who control the basic definitions of policy and decisions and those who disagree with those policies. Briefly and oversimply, we expected that in the more custodial institutions social service workers and teachers would conflict with cottage parents but not with each other, and that in treatment institutions cottage parents and teachers would conflict with the powerful social service staff but not with each other. In a milieu institution, however, where cottage parents and social service workers are highly integrated, we expected that both would be likely to conflict with teachers but not with each other. These are oversimplified explanations, however, because they make assumptions which are not necessarily met. They assume, for example, that the values of social serv- 
ice workers in a custodial institution will conflict with those of the cottage parents, while in reality institutions may select and train people who can accommodate to the institution. In other words, our predictions would hold true only if these groups did, in fact, have divergent values. Secondly, we had assumed that groups interact and recognize the conflict, but if groups are relatively isolated, the partners to the conflict would not be aware of it.

In general, our model worked. In those cases where it did not, we could see that the institution's selection policies had solved the problem. For instance, in the individual treatment institution, we had expected a great deal of conflict between the cottage parents and the social service workers, but since the cottage parents were all college-educated persons who identified with the professional staff and accepted their professional ideals, this institution effectively by-passed such conflict. This does not mean that the cottage parents failed to experience a large degree of role strain; they did feel pressured, were not sure what they were supposed to be doing, and so on. Since they accepted the values of the social service staff, however, they could not come out in open conflict with them. The one case in which we clearly were wrong was the milieu institution: there, cottage parents and social service workers continued to be in conflict even though we had expected them not to be and even though they identified with each other and considered themselves part of the same team. So although they continued to fight, they felt they were fighting on the same side and for the same goals and they attempted to reconcile their differences.

\section{Staff-Inmate Relationships}

In testing out some of our commonsense assumptions about what relationships of staff to inmates would obtain in different organizations, we found that in custodial institutions staff had a relatively dominating relationship with the inmates, while in treatment institutions staff were less domineering and relied more on manipulation and persuasion to control the inmates. To illustrate, in custodial institutions all staff are called "sir" or "ma'am" by the boys, reflecting the emphasis upon social distance; in treatment institutions friendlyand sometimes not so friendly-nick. names are permitted. In the most custodial institution one of the staff members, who was well-liked by both staff and boys, was ordered to paddle any boy who called him by his nickname-a nickname which all the staff used in front of the boys.

These differences in basic relationships were reflected in the staff attitude toward the inmates. Thus, the staff in the more custodial institutions felt that boys should keep to themselves, should conform, should not make too many friends within the institution, and should not have close relationships with many people. Staff in the more treatment-oriented institutions wanted boys to make friends with both the staff and the other boys and to express themselves, articulate their needs, and so on. They also stressed the importance of understanding the boys more than did those in the custodial institutions.

Another difference is subtle. In all the institutions studied, staff were preoccupied with two kinds of inmatesthe boy who is quiet and the boy who makes himself known. The quiet, withdrawn boy generally does not get 
too much attention, although the staff in treatment institutions try to encourage this type of child to come out of himself, to start acting up a little, if you will. Custodial institutions tend to ignore this type of boy. The reasoning used by the treatment personnel is that if a boy is just quietly getting by, the institution is not actually reaching him. He is just "doing time."

In all institutions, however, when staff are among themselves, it is not the quiet one they talk about, but the troublemakers and the heroes who, in all the institutions, tended to be the good athletes. But personnel in the treatment and custodial institutions have fundamentally different attitudes toward the troublemakers. Although staff in custodial institntions tend to talk about them with awe, the only problem they worry about is how to stop them. For the staff in the treatment institution, trouble-making reflects underlying disturbance and is not something to be clamped down on immediately. To know what is bothering the inmate, one must almost encourage disturbance.

\section{Inmate Response}

How do differences in goal $\mathrm{empha-}$ sis affect the behavior of the inmates? Instead of stretching our resources to gather data on inmate recidivism, we chose to focus on the attitudes and social relations of the inmates while they were in the institution. Findings in this area, we believe, have implications for the inmates' future adjustment.

We asked the inmates a variety of questions as to whether the institution was a better or worse place than they expected, whether they thought the institution had been of some help to them, whether staff members were fair, and other subjects. From the replies, we found that the attitudes of inmates in custodial institutions were less favorable than the attitudes of the inmates in treatment organizations. Further, we found that among the inmates of custodial institutions, those who were more involved in or who were informal leaders of the in. mate group were even more antipathetic toward that type of institution than were the other inmates. By contrast, the more involved inmates and leaders in the treatment institutions had more favorable attitudes than the other boys. Overall, then, the results of our inmate questionnaire showed a consistent pattern of differences in inmate attitudes toward themselves, the institution, and the staff, depending on the type of institutions they were in. In the custodial institutions emphasizing containment and conformity, the inmate group, by stressing covert opposition and "playing it cool," moved toward behavior more consistent with the institutional policy than did inmates in the treatment institutions. The custodial inmates thus made little move to alter their behavior, while the inmate group in the treatment facility seemed to influence its members toward achieving change, at least insofar as change in behavior requires some cooperation with the staff.

Of special interest were our findings on the ways in which the formal organizational structure influences the informal patterns of inmate social relations. The results clearly challenge the frequently held view that the inmate group is inevitably opposed to the goals of the organization. First, the degree of inmate solidarity against the administration in juvenile institutions was nowhere as high as 
that reported generally for adult prisons. Second, solidarity-the inmates' belief that they should and do stick together-was not necessarily linked to attitudes opposed to the institution and staff. Third, solidarity was higher in the treatment institutions, where, as we have suggested, inmate attitude was relatively more favorable than it was in the custodial institutions. Finally, in the custodial organizations the staff's repression of inmate social relations effectively reduced the level of inmate solidarity but at the same time tended to assure that whatever inmate group activity did take place would be oriented against the institution and staff. By contrast, in the treatment institutions, where the inmates were allowed to organize and express hostility overtly, the boys apparently were more day-to-day "trouble" to the staff, but their groupings were less often oriented against the institution and staff and had fewer undesirable effects upon the inmates' attitudes.

Differences between the inmates in the two custodial and two treatment institutions were clear-cut, and our findings for inmates in the two small open institutions paralleled those for the inmates in the treatment institutions. Inmates in these open organizations were almost as favorably dis. posed to their environment as those in the treatment institutions- $a$ finding which raises the question of whether the great resources used for treatment are really necessary if the same results are produced in an open institution.

This paper is not a prescription for running a correctional institution. Rather, it points to dilemmas which arise from the various goals which institutions set for themselves. Today, professionalization of correctional personnel is leading toward a greater emphasis upon rehabilitation and treatment so that few institutions will be able to cling to predominantly custodial goals in the years ahead. Yet, any executive who wants to move his institution toward treatment goals must be prepared to face conflict among staff members, higher operating costs, and the need for, and risks in, delegating authority. But the effort, as our study indicated, will be worth it. 